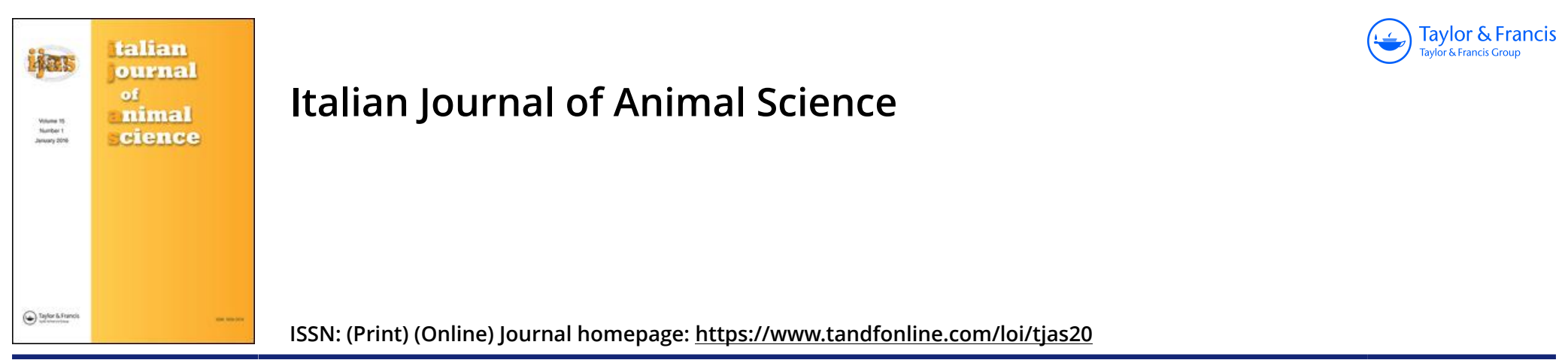

\title{
Effect of does parity order on litter homogeneity parameters
}

\author{
Marta Pollesel , Marco Tassinari , Andrea Frabetti , Daniela Fornasini \& \\ Damiano Cavallini
}

To cite this article: Marta Pollesel, Marco Tassinari , Andrea Frabetti, Daniela Fornasini \& Damiano Cavallini (2020) Effect of does parity order on litter homogeneity parameters, Italian Journal of Animal Science, 19:1, 1189-1195, DOI: 10.1080/1828051X.2020.1827990

To link to this article: https://doi.org/10.1080/1828051X.2020.1827990
(c) 2020 The Author(s). Published by Informa UK Limited, trading as Taylor \& Francis Group.

\section{曲 Published online: 06 Oct 2020.}

Submit your article to this journal

Q View related articles $\asymp$

View Crossmark data $\nearrow$ 


\title{
Effect of does parity order on litter homogeneity parameters
}

\author{
Marta Pollesel ${ }^{a}$, Marco Tassinari ${ }^{a}$, Andrea Frabetti ${ }^{b}$, Daniela Fornasini ${ }^{b}$ and Damiano Cavallini ${ }^{a}$

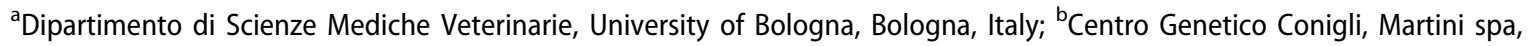 \\ Ferrara, Italy
}

ABSTRACT

In rabbits' reproductive performance, litter size, birth weight, growth, and mortality rate are among the most important indicators to define the productive potential and they are associated with parity order. Birth weight and little size are valuable parameters as related to mortality and weaning weight. Thus, it is important to study individual newborn and intra-litter homogeneity parameters. This trial aimed to consider the litter homogeneity weight at birth, both within each litter and in the whole population, in order to suggest new proper within-litter homogenisation parameters. In this study, the 1st and 6th parity order had, respectively, the lowest and highest values in litter size $(8.96$ vs $12.39, \mathrm{n})$, born-alive $(8.36$ vs 12.22 , n), litter weight $(456.4 \mathrm{~g}$ vs 719.8 , g), born-alive weight, and quartiles' homogeneity. These parameters decreased in greater parity orders. No significant effects on still-born numbers and mortality rates were evidenced. All these litter homogeneity evaluation parameters appeared interesting in describing differences between parity orders. The results confirmed that does parity order influences litter size and born-alive weight, but also the intra- and inter-litter homogenisation. Litter homogenisation is crucial to ensure a proportionate share of milk, more equal growth, and better productive performances. Based on these results, we suggest for the commercial genetic centres to equalise the litters according to the birth weight, by dividing the population into quartiles and rearing kits with light birth weight in smaller litters and those with heavier birth weight in larger litters.

\section{HIGHLIGHTS}

- Does parity order influences litter size and born-alive weight

- Kit's quartiles distribution is a useful tool for equalisation practice

Abbreviations: Prim: primiparous does; Plur: pluriparous does; Al: artificial insemination; LS: litter size; LW: litter weight; MR: mortality rate; BA: born-alive number; SB: still-born number; BAW: born-alive weight; mn-BAW: mean born-alive weight; sd-BAW: intra-litter standard deviation born-alive weight; 1st q-BAW: first quartile born-alive weight; 3rd q-BAW: third quartile bornalive weight
ARTICLE HISTORY

Received 11 April 2020

Revised 14 September 2020

Accepted 21 September 2020

\section{KEYWORDS}

Rabbit; does reproduction; parity order; litter homogeneity; kits viability

\section{Introduction}

In the last decades, breeding strategies have been implemented in the rabbit industry to increase its efficiency and sustainability. In Italy, the genetic selection is operated by 'Libro Genealogico della specie cunicola' (D.M. 18.11.72) and then demanded to the Italian Breeders Association (Associazione Italiana Allevatori, D.M. 24.11.1981). However, concurrently to this activity, private companies have implemented selection lines and produced patented hybrids.

Reproductive performance of rabbit does (Castellini et al. 2010), milk production and quality (Ludwiczak et al. 2020), as well as litter size (LS) and litter weight at birth (LW), growth rate and mortality rate (MR), are useful indicators of the productive potential within a rabbit farm (Rebollar et al. 2009; Szendrő et al. 2019). In rabbits, the variation of LW, individual LW, and LS are associated with parity order; for example, LS is substantially lower in the first kindling compared to the subsequent litters (Szendrö 2000). Moreover, LS increases with parity number, while the average weight of kits born alive decreases (Xiccato et al. 2004). Individual birth weight is about $60-70 \mathrm{~g}$, but it can range from 35-40 to 80-90 g (Poigner et al. 2000a,b).

Breeding strategies have successfully contributed to increasing LS and number of born kits (total or alive);

CONTACT Dr. Damiano Cavallini damiano.cavallini@unibo.it E Dipartimento di Scienze Mediche Veterinarie, University of Bologna, via Tolara di Sopra 50, Ozzano dell'Emilia, BO, 40064, Italy

(C) 2020 The Author(s). Published by Informa UK Limited, trading as Taylor \& Francis Group.

This is an Open Access article distributed under the terms of the Creative Commons Attribution License (http://creativecommons.org/licenses/by/4.0/), which permits unrestricted use, distribution, and reproduction in any medium, provided the original work is properly cited. 
however, weight at birth, particularly in larger litters, is still less homogeneous (Vicente et al. 1995; Lenoir et al. 2012). High birth weight represents a basic parameter in the management of a rabbit farm, because it is associated to lower MR (Szendrö et al. 1996; Di Meo et al. 2004) and to higher weight at weaning (Di Meo et al. 2004). For example, Szendrő and Barna (1984) observed an MR of about $50 \%$ in young rabbits between 35 and $45 \mathrm{~g}$ due to the reduction of energy reserves and consequently of the thermoregulatory capacity, while beyond this weight the MR reduced to 7\%. Moreover, LS is correlated to the weight gained by suckling rabbits at weaning: indeed, kits of larger and heterogeneous litters are generally characterised by lower weight at weaning than kits of smaller litters for the corresponding weight (Poigner et al. 2000a,b; Szendrö et al. 2019). This is due to the chance of kits to find an available teat during suckling period and on their milk intake (Ludwiczak et al. 2020). LS is negatively associated to the individual milk share (Lebas 1975, Ferguson et al. 1997), due to reduced access to the teat (Szendrö and Kampits 1985) and heterogenous kits size (Lenoir et al. 2012; Blasco et al. 2017). At the same time, LS increase is connected with several problems related to the health status and welfare of does lead to high rates of mortality in their offspring, high rate of culling and a low rate of production (Minuti et al. 2020).

For these reasons, it is of primary importance to obtain a high individual weight and an intra-litter homogeneity weight at birth in order to reduce the $M R$, to increase the weight at weaning and, consequently, to improve the productive potential of the farm (Szendrö et al. 2019). A relevant number of studies have been published on the relationship between parity order and LS, and on LW and at weaning (Poigner et al. 2000a,b; Di Meo et al. 2004; Szendrö et al. 2019). Bolet et al. (2007), investigated the effectiveness of genetic selection for higher uniformity of birth weight within-litter and they concluded that breeding strategies aiming at decreasing the within-litter standard deviation of birth weight have positive implications on the reproductive performance of rabbit does. A way to reduce the high MR due to low birth weight is the practice of litter equalisation, applied in many rabbit farms. In this way, the rabbit does nurse the same number of newborn kits with a similar weight. As a result of equalisation, the heavier kits do not suppress the weak contemporaries, so the latter has a similar chance of survival, having more chance to access a teat during the short nursing time (Szendrö et al. 2019). Researchers demonstrate that in the homogenised litter for birth weight, mortality in the pre-weaning period is reduced from 13.3 to $10 \%$, compared to heterogeneous litters (Poigner et al. $2000 a, b)$. Even though equalisation is a widespread procedure, only limited experimental results have been published (Szendrö et al. 2019).

Although the effect of the parity order on reproductive parameters has previously been studied in rabbits, the aim of our research was to study in field conditions the litter homogeneity and the possibility to introduce the quartile's distribution as a novel inter-litter homogeneity tool.

\section{Materials and methods}

The trial was carried out at the farm level, under the control of the public veterinary service, and did not need approval by the University of Bologna, Animal Care, and Use Committee, according to Italian legislation (D.lgs. 26/2014).

\section{Rearing building, equipment and management}

The trial was carried out in Martini Group S.p.A. genetic centre located in the Emilia Romagna region (Italy). The commercial hybrid line (Genetica Martini hybrid, Santa Maria Codifiume, FE, Italy) is characterised by a high specialisation in meat production $(44 \mathrm{~g} /$ $\mathrm{d}$ of average daily gain with peaks up to $60 \mathrm{~g} / \mathrm{d}$ ), white colour and the adult body weight of 4.5 and $6 \mathrm{~kg}$ for females and males, respectively. Hybrid lines were homogeneous and internally selected by the genetic centre. The artificial insemination (Al) protocol adopted during the trial was composed as follows. Briefly, nulliparous does start the reproduction program when aged 19-20 weeks and weighted $3.7-3.8 \mathrm{~kg}$, males when aged 10 weeks with at least $3.2 \mathrm{~kg}$. The average open does' weight was 3.8 and $4.5 \mathrm{~kg}$ for primiparous and pluriparous, respectively. Does were Al $11 \mathrm{~d}$ after kindling. The does were housed in two different brick sheds with a temperature ranging between $18-28^{\circ} \mathrm{C}$, with a conditioning air system and submitted to a constant photoperiod of 16-h light and 8-h darkness. The animals were kept in individual cages from $\mathrm{Al}$ to parturition. Does were bred individually, in cages $\left(410 \times 940 \times 400 \mathrm{~mm}^{3}\right)$ made of galvanised wire net equipped with automatic drinker and manual feeder. The cages were equipped with a nest box $\left(410 \times 210 \times 300 \mathrm{~mm}^{3}\right)$ made of galvanised sheet walls and a double wire floor, with manual closure. The nest was prepared with a mixture of wood shavings and chopped straw, and it was 
Table 1. Composition of the diets fed to does (as fed).

\begin{tabular}{lcc}
\hline & Lactation $^{\text {a }}$ & Pre-weaning $^{\text {b }}$ \\
\hline Chemical composition, \% & & \\
Crude protein, \% & 17.30 & 16.20 \\
Ether extract, \% & 3.90 & 3.30 \\
Ash, \% & 7.80 & 8.20 \\
Crude fibre, \% & 15.6 & 17.30 \\
Calcium, \% & 0.97 & 1.20 \\
Phosphorus, \% & 0.55 & 0.54 \\
Sodium, \% & 0.21 & 0.21 \\
Lysine, \% & 0.78 & 0.77 \\
Methionine, \% & 0.29 & 0.26 \\
Vitamins, minerals and additives, per kg & & \\
Vit. A, Ul & 15,000 & 15,000 \\
Vit. D3, Ul & 1500 & 1500 \\
Vit. E, mg & 90 & 100 \\
Mn, mg & 50 & 50 \\
Zn, mg & 70 & 70 \\
Co, mg & 0.13 & 0.13 \\
Cu, mg & 10 & 10 \\
Fe, mg & 150 & 150 \\
l, mg & 3 & 3 \\
Se, mg & 0.10 & 0.10 \\
Robenidine cloridate, mg & 66 & 66 \\
Formic acid, mg & 1125 & 1125 \\
\hline
\end{tabular}

atactation diet ingredients: wheat bran, alfalfa meal, barley, partially decorticated sunflower extraction meal, decorticated sunflower extraction meal, dehydrated alfalfa meal, wheat middling, dehydrated beat pulp, grass hay meal, cane molasses, wheat, corn oil, calcium carbonate, sodium chloride, palm oil, magnesium oxide.

${ }^{\text {b} P r e-w e a n i n g ~ d i e t ~ i n g r e d i e n t s: ~ p a r t i a l l y ~ d e c o r t i c a t e d ~ s u n f l o w e r ~ e x t r a c t i o n ~}$ meal, wheat bran, barley, dehydrated beat pulp, dehydrated alfalfa meal, alfalfa meal, wheat middling, grapeseed extraction meal, grass hay meal, cane molasses, decorticated sunflower extraction meal, calcium carbonate, corn oil, sodium chloride, magnesium oxide.

attached to the front side of the maternal cage just before kindling. Until the 10th day of pregnancy, they are fed ad-libitum with the 'Lactation diet', then with the 'Pre-weaning diet'; the latest contained almost the same ingredients as the first one but at different inclusion rates. The chemical composition and nutritive value of the diets followed the recommendations of De Blas and Mateos (1998), listed in Table 1. The chemical analysis of the two diets was made according to the AOAC official methods (AOAC International 2016) for dry matter (oven drying method), ash (muffle furnace incineration), ether extract (solvent extraction), crude protein (Kjeldahl method) and crude fibre (Weende method) determinations.

\section{Animals and experimental measurements}

The measurements were performed twice in spring, within 15 days from each other, according to the insemination protocol used in the genetic centre, previously explained. All the parturient does that were in the centre on those dates were enrolled in the study. Does' individual weight was not recorded to avoid an excess of stress to the commercial farm animals. A total of 531 does, delivering 5301 kits, at different parity orders were involved; $176(33.15 \%)$ primiparous and 355 (66.85\%) pluriparous (from the 2nd to the 17th parturition). The proportions of the pluriparous were the following: $15.63 \%$ 2nd, $15.63 \%$ 3rd, $10.73 \%$ 4th, $11.86 \%$ 5th, $6.78 \%$ 6th, $3.39 \%$ 7th, $5.46 \%$ 8th, $4.33 \%$ 9th and $3.77 \%$ from the 10th to the 17 th parturition, that due to low numerosity were grouped in the same group $(1.88 \% 10$ th, $1.13 \% 11$ th, $0.38 \% 12$ th, $0.19 \% 13$ th and $0.19 \% 17$ th parturition).

Within 24 hours from the delivery, the reproductive and litters data, for example, LS, born-alive number $(\mathrm{BA})$, and still-born number (SB) per delivery, were recorded. Each born-alive kit was individually weighed using an electronic scale of $3000 \mathrm{~g}$ capacity and $1 \mathrm{~g}$ resolution (Soehnle, Nassau an der Lahn, Germany). Total LW was calculated as the sum of all individual alive newborn weights within the litter. The MR was calculated as SB/LS $\times 100$. The other parameters evaluated in the present study were (i) number of born-alive kits $<45 \mathrm{~g}$ (BAW $<45 \mathrm{~g} \mathrm{n}$ ); (ii) percentage of born-alive kits $<45 \mathrm{~g}$ (BAW $<45 \mathrm{~g} \%$ ); (iii) Mean born-alive weight (mn-BAW); (iv) standard deviation born-alive weight (sdBAW); (v) and (vi) 1st and 3rd quartiles born-alive weight number (1st and 3rd q-BAW n); (vii) and (viii) 1st and 3rd quartiles born-alive weight number (1st and 3rd q-BAW \%).

Considering the entire sample, mn-BAW, intra-litter sd-BAW, and 1st and 3rd q-BAW resulted on average $59.39,12.57,51$, and $58 \mathrm{~g}$, respectively. The 1st and 3rd q-BAW thresholds were used for comparing each BAW grouped by parity order. The born-alive distribution parameters 1st-3rd q-BAW, $<1$ st q-BAW, $>3 r d$ qBAW, number $(n)$ and percentage (\%) were evaluated. Kits included in 1st-3rd q-BAW represented the population part most homogeneous in weight; this part is between the $25 \%$ lighter $(<1 \mathrm{st} \mathrm{q}-\mathrm{BAW}=51 \mathrm{~g})$, and the $25 \%$ heavier $(>3 \mathrm{rd}$ q-BAW $=68 \mathrm{~g}$ ).

\section{Statistical analysis}

This study aimed to describe litter homogeneity parameters into a commercial farm in one-shot data collection, so no effects on replicate and seasonality were considered.

The variables LS, BA, SB, MR, LW, BAW $<45 \mathrm{~g} n$, BAW $<45 \mathrm{~g} \%$, mn-BAW, sd-BAW and 1st and 3rd q-BAW, and related parameters, were firstly tested for normality and homoscedasticity with the Shapiro-Wilk's and Levene's test, respectively. One way ANOVA procedure was employed to test the effect of parity order on the aforementioned parameters. Significant differences were declared for $p<.05$, highly significant for $p<.01$ 
and trends for $p<.10$ were noticed. Tukey's multiple comparison test was used for paired comparison of parity order means and the level of significance was determined at $p<.05$. All data were processed using R Studio.

\section{Results}

The effect of different parity order on $L S, B A, S B, M R$, $\mathrm{LW}$, and BAW $<45 \mathrm{~g} \mathrm{n}$ and $\%$ are reported in Table 2 . With the exception of SB and MR, the effect of parity order was highly significant $(p<.01)$ for all traits considered in the present study. Both LS and MR were at their minimum in the 1st parturition (8.96 and 8.36, respectively), then gradually increased, except for the 5th parity (LS), until the 6th parity order, when the maximum values were reached (12.39 and 12.22, respectively). After the 7th parity order, these parameters decreased significantly. Total LW significantly increased among parity orders $(p<.01)$, and peaked at the 6 th $(719.78 \mathrm{~g})$ parturition, to subsequently decrease.

Both BAW $<45 \mathrm{~g} n$ and \% were significantly associated with parity order $(p<.01)$. The highest values of these parameters occurred in the 1st parturition (1.83 and 18.69, in BAW $<45 \mathrm{~g} n$ and \%, respectively). The number of born-alive kits, which was the lowest in primiparae (8.36), increased up to the sixth parity (12.22) to decrease thereafter.
The results reported in Table 3 on mn-BAW, sdBAW, 1st-3rd q-BAW ( $n$ and \%), <1st q-BAW ( $n$ and $\%$ ) and $>3$ rd q-BAW ( $n$ and \%) considered kits distribution relationship with the whole population. The mn-BAW was the lowest at 1st parturition. Similar results were observed in sd-BAW, where the minimum value was again in the 1 st parturition $(p<.01)$. Considering 1st-3rd q-BAW (n), differences between parity effect levels have been detected only between the 1 st and 2 nd (4.27 vs 5.54 , respectively), and the 1st and the 6th order (4.27 vs 7.39 respectively; $p<.01$ ). Primiparous does had the lowest number of kits included in this range (4.27), while does at the 6th parturition had the highest value (7.39).

The 1st quartile results $(n)$ were statistically different in the primiparous group compared to the 3rd and the 4th parturitions $(p<.01)$. Many primiparous' kits were included in the 1st quartile (3.16), while the $3 \mathrm{rd}$ and 4th parity order had the lowest incidences (1.69 and 1.53 , respectively). Percentage values were similar: primiparous had the highest percentage $(32.69 \%)$ of kits belonging to the 1st quartile compared to the pluriparous does (15.46\% on average). Complementary results were reported in values above the 3rd quartile $(p<.01)$. In this case, the 1 st parturition does have the lowest number of kits below the 3rd quartile (0.97 > 3rd q-BAW), while does in 3rd, 4th and 7th parity orders had the highest values (3.31, 3.75 and 3.69, 3rd q-BAW, respectively). Similar results were observed

Table 2. Effect of parity order on litter performance.

\begin{tabular}{|c|c|c|c|c|c|c|c|c|c|c|c|c|}
\hline \multirow[b]{2}{*}{ Item } & \multicolumn{10}{|c|}{ Parity order } & \multirow[b]{2}{*}{ SEM } & \multirow[b]{2}{*}{$p$} \\
\hline & 1 & 2 & 3 & 4 & 5 & 6 & 7 & 8 & 9 & $>9$ & & \\
\hline $\mathrm{LS}, n$ & $8.96^{\mathrm{B}}$ & $10.26^{A}$ & $10.23^{A B}$ & $10.94^{A}$ & $9.91^{\mathrm{AB}}$ & $12.39^{A}$ & $11.00^{\mathrm{A}}$ & $10.52^{\mathrm{AB}}$ & $10.08^{A B}$ & $9.80^{\mathrm{AB}}$ & 0.47 & $<.01$ \\
\hline $\mathrm{BA}, n$ & $8.36^{C}$ & $9.64^{\mathrm{B}}$ & $9.64^{\mathrm{BC}}$ & $10.39^{\mathrm{AB}}$ & $9.66^{\mathrm{ABC}}$ & $12.22^{\mathrm{A}}$ & $10.76^{A B}$ & $9.91^{\mathrm{ABC}}$ & $9.92^{\mathrm{ABC}}$ & $9.25^{\mathrm{ABC}}$ & 0.49 & $<.01$ \\
\hline $\mathrm{SB}, n$ & 0.60 & 0.62 & 0.59 & 0.56 & 0.26 & 0.17 & 0.24 & 0.61 & 0.15 & 0.55 & 0.24 & .71 \\
\hline MR, \% & 6.22 & 6.17 & 6.25 & 4.96 & 2.60 & 1.28 & 2.46 & 6.81 & 1.35 & 4.22 & 2.30 & .54 \\
\hline LW, g & $456.40^{C}$ & $582.6^{\mathrm{B}}$ & $616.80^{A B}$ & $655.80^{\mathrm{AB}}$ & $598.50^{A B}$ & $719.80^{A}$ & $659.90^{A B}$ & $610.40^{\mathrm{AB}}$ & $622.10^{\mathrm{AB}}$ & $581.40^{\mathrm{AB}}$ & 23.11 & $<.01$ \\
\hline BAW $<45 \mathrm{~g}, n$ & $1.83^{\mathrm{A}}$ & $1.35^{\mathrm{AB}}$ & $0.84^{\mathrm{AB}}$ & $0.88^{\mathrm{B}}$ & $1.20^{\mathrm{AB}}$ & $1.67^{A B}$ & $1.41^{\mathrm{AB}}$ & $0.83^{A B}$ & $0.62^{A B}$ & $0.90^{\mathrm{AB}}$ & 0.34 & $<.01$ \\
\hline $\mathrm{BAW}<45 \mathrm{~g}, \%$ & $18.69^{A}$ & $12.44^{\mathrm{AB}}$ & $7.67^{B}$ & $7.20^{\mathrm{B}}$ & $10.31^{A B}$ & $11.76^{\mathrm{AB}}$ & $10.05^{A B}$ & $6.98^{\mathrm{AB}}$ & $5.51^{\mathrm{B}}$ & $9.51^{\mathrm{AB}}$ & 2.97 & $<.01$ \\
\hline
\end{tabular}

$\overline{A, B, C}$ Values within rows with different superscripts differ $(p<.05)$

LS: litter size; BA: born-alive; SB: still-born; MR: mortality rate; LW: litter weight; BAW $<45 \mathrm{~g}$ : born-alive weight $<45 \mathrm{~g}$.

Table 3. Effect of parity order on litter distribution parameters.

\begin{tabular}{|c|c|c|c|c|c|c|c|c|c|c|c|c|}
\hline \multirow[b]{2}{*}{ Item } & \multicolumn{10}{|c|}{ Parity order } & \multirow[b]{2}{*}{ SEM } & \multirow[b]{2}{*}{$p$} \\
\hline & 1 & 2 & 3 & 4 & 5 & 6 & 7 & 8 & 9 & $>9$ & & \\
\hline mn-BAW, g & $56.23^{B}$ & $61.54^{\mathrm{A}}$ & $64.36^{A}$ & $64.17^{\mathrm{A}}$ & $63.78^{\mathrm{A}}$ & $59.56^{\mathrm{AB}}$ & $63.07^{A}$ & $63.51^{\mathrm{A}}$ & $64.63^{A}$ & $64.53^{\mathrm{A}}$ & 1.64 & $<.01$ \\
\hline sd-BAW, g & $6.83^{\mathrm{B}}$ & $8.25^{\mathrm{A}}$ & $8.60^{A}$ & $9.17^{\mathrm{A}}$ & $8.84^{\mathrm{A}}$ & $9.04^{\mathrm{AB}}$ & $9.49^{\mathrm{A}}$ & $7.97^{\mathrm{AB}}$ & $8.94^{\mathrm{A}}$ & $7.98^{\mathrm{AB}}$ & 0.51 & $<.01$ \\
\hline 1 st-3rd q-BAW, $n$ & $4.27^{C}$ & $5.54^{\mathrm{AB}}$ & $4.82^{\mathrm{BC}}$ & $5.11^{\mathrm{ABC}}$ & $4.66^{\mathrm{BC}}$ & $7.39^{A}$ & $4.90^{\mathrm{ABC}}$ & $5.91^{A B C}$ & $5.23^{\mathrm{ABC}}$ & $4.70^{\mathrm{ABC}}$ & 0.48 & $<.01$ \\
\hline 1 st-3rd q-BAW, \% & 51.28 & 51.63 & 46.31 & 47.45 & 46.67 & 61.59 & 43.87 & 54.89 & 49.51 & 46.77 & 4.42 & .44 \\
\hline$<1$ st q-BAW, $n$ & $3.16^{\mathrm{A}}$ & $2.34^{\mathrm{AB}}$ & $1.69^{B}$ & $1.53^{\mathrm{B}}$ & $1.77^{\mathrm{AB}}$ & $2.39^{\mathrm{AB}}$ & $2.17^{\mathrm{AB}}$ & $1.61^{\mathrm{AB}}$ & $1.58^{\mathrm{AB}}$ & $1.25^{\mathrm{AB}}$ & 0.46 & $<.01$ \\
\hline$<1$ st q-BAW, \% & $32.69^{A}$ & $20.65^{\mathrm{B}}$ & $15.25^{\mathrm{B}}$ & $12.79^{B}$ & $15.38^{B}$ & $17.74^{\mathrm{AB}}$ & $16.44^{\mathrm{B}}$ & $13.98^{\mathrm{B}}$ & $13.94^{\mathrm{B}}$ & $12.94^{\mathrm{B}}$ & 4.00 & $<.01$ \\
\hline$>3 r d q-B A W, n$ & $0.97^{C}$ & $2.00^{\mathrm{B}}$ & $3.31^{\mathrm{A}}$ & $3.75^{\mathrm{A}}$ & $3.23^{\mathrm{AB}}$ & $2.44^{\mathrm{ABC}}$ & $3.69^{\mathrm{A}}$ & $2.39^{A B C}$ & $3.12^{\mathrm{AB}}$ & $3.30^{\mathrm{AB}}$ & 0.35 & $<.01$ \\
\hline$>3 r d q-B A W, \%$ & $16.03^{B}$ & $27.73^{A B}$ & $38.44^{\mathrm{A}}$ & $39.76^{\mathrm{A}}$ & $37.96^{\mathrm{A}}$ & $20.66^{A B}$ & $39.69^{A}$ & $31.14^{\mathrm{AB}}$ & $36.55^{\mathrm{A}}$ & $40.29^{\mathrm{A}}$ & 5.01 & $<.01$ \\
\hline
\end{tabular}

$\mathrm{A}, \mathrm{B}, \mathrm{C}$ Values within rows with different superscripts differ $(p<.05)$.

mn-BAW: mean born-alive weight; sd-BAW: intra-litter standard deviation born-alive weight; 1st-3rd q-BAW: born-alive weight between first and third quartile; <1st q-BAW: born-alive weigth below first quartile; >3rd q-BAW: born-alive weight above third quartile. 
for the percentage values $(p<.01)$ : only the $16.03 \%$ of kits in the primiparous group belonged to the 3rd quartile, compared to pluriparous (34.69\% on average).

\section{Discussion}

The objective of the present study was to quantify the effect of does parity order on large farm inter and intra-litter homogeneity parameters. This effect was statistically significant for almost all the traits analysed, except for SB, MR, and 1st-3rd q-BAW \%.

The least-square means of the different parity orders on does' reproductive performances are generally in slight disagreement compared to those reported in previous studies. The overall mean LS $(\sim 10)$ and LW ( $\sim 610 \mathrm{~g})$ was higher compared to Tůma et al. (2010) and Dalle Zotte and Paci (2013), who evaluated does reproductive parameters on the same season. Moreover, the research by Blasco et al. (2017) reported smaller LS across parity orders compared to the present study. Such differences are probably related to the different genetic types used across studies.

The association between parity order and reproductive reported in the current research is generally in agreement with the existing literature, indicating a positive relationship between parity order increase and LS and LW at birth (Szendrö 2000; Tüma et al. 2010; Minuti et al. 2020). The 1st parturition had the lowest values in LS, BA, LW, and mn-BAW, according to Szendrő (2000), Xiccato et al. (2004) and Dalle Zotte and Paci (2013). It is known that, when rabbit does begin their reproductive life, they usually have not achieved their total body development yet (Rebollar et al. 2009, Castellini et al. 2010) and, for this reason, the litter parameters (such as LS, BA, and LW) are lower compared to the subsequent parturitions. This was confirmed also in the present study, were LS, BA and LW peaked in the 6th parturition when does have already achieved adult body size. Subsequently, LS, BA and LW started to decrease. Our results are in partial accordance with Tuma et al. (2010), but on disagreement with Szendrö (2000), who reported a decrease of LS, BA, and LW after the 3rd kindling. Such differences are probably related to the meat production genetic type used.

Oppositely, mn-BAW did not differ from the 2nd parturition, confirming that kits mean weight does not change across the parity order, except for the first one. In completely accordance with our results, ParigiBini and Xiccato (1993) observed a 10\% difference in birth weight between 1st and 2nd litter (56.6 and
$62.8 \mathrm{~g}$ respectively) and Vasquez et al. (1997) found a $6 \%$ difference in birth weight between primiparous and multiparous does. On the other hand, Zerrouki et al. (2007, 2010), Sivakumar et al. (2013) and Apori et al. (2014) recorded a longer effect of parity order with a continuous increase until the 4th-6th parturition.

It is although reported by Szendrö et al. (2019) that in larger litters the average birth weight decreased and that birth weight is related to several behavioural patterns, productive and reproductive traits, such as the kits' behaviour in the nest, their nursing and milk intake, mortality, live performance along with growth, carcase traits and meat quality and reproductive performance of rabbit does.

Our results demonstrated an increase in sd-BAW after the 1st parturition, according to the findings of Lenoir et al. (2012), where the sd-BAW increased significantly in larger litters. Moreover, Vicente et al. (1995) and Poigner et al. (2000a,b) described the same trend, but the standard deviation did not increase in the largest litters.

In our study, there was no significant effect of parity order on SB and MR, in accordance with Dalle Zotte and Paci (2013). However, both LS and birth weight affected mortality in suckling rabbits (Poigner et al. 2000a,b). Nevertheless, our results need more data for a deeper evaluation because SB and MR play an important role in genetic center management. Indeed, a proper within-litter homogenisation based on birth weight resulted in lower MR in previous studies (Garreau et al. 2008).

Primiparous does have litters with the highest number and percentage of kits below $45 \mathrm{~g}$, increasing the chance of kits mortality (Szendro" and Barna 1984; Poigner et al. 2000a,b). In fact, the probability of individual survival is related to birth weight, as the kits with lower birth weight have a lower probability of survival (Agea et al. 2019). This was observed also in the current study, although the effect of parity was not statistically significant on MR. Kits with a low birth weight have many disadvantages compared to those with medium or heavy birth weight at birth. Firstly, its viability is weak. Moreover, low birth weight kits suckle less than heavier littermates, and, generally, they consume less milk (Szendrő et al. 2019; Ludwiczak et al. 2020).

To reduce mortality and to achieve more balanced growth in litters and stocks, it is advisable to equalise the litters according to the birth weight, by rearing kits with lighter birth weight in smaller litters and those with heavier birth weight in larger litters (Szendrő et al. 2019). 
Without litter homogenisation, Szendrö and Barna (1984) observed that all kits with a birth weight under $35 \mathrm{~g}$ died during the first week of life, the mortality was higher than $50 \%$ in groups of kits weighting between 35 and $50 \mathrm{~g}$, and nearly $10 \%$ or lower when the birth weight was more than $50 \mathrm{~g}$. Moreover, neonates require a protective environment, adequate nutrition, and special maternal care in order to survive (Hamilton et al. 1997). If the birth weight is lower than the optimum weight, the energy reserves and the thermoregulatory capacity are reduced, and the perinatal mortality increases (Vicente et al. 1995).

Since homogeneity evaluation is important not only within each litter but also for the entire population, kits' weight at birth was compared across the different parity orders using quartiles. Litter homogeneity was related to the number of kits in the 1 st-3rd quartile range: the more kits were in this range, the more homogeneous the litter was. On such an aspect, important differences among the parity orders were noticed in the present study. In particular, primiparous does have smaller litters with lighter kits, homogeneous between them, but heterogeneous compared to the remaining part of the population. On the other hand, does in other parity orders shared similar characteristics, such as larger litters and heavier kits at birth. Litters of does in the 6th parturition were the most homogeneous, while the 3rd, 4th and 7th included few light kits and many heavy kits. It is well known that there is a positive correlation between survival and uniformity of weight at birth, without affecting individual and LW (Agea et al. 2019). In fact, Bolet et al. (2007) found a negative correlation between LS and mn-BAW and an increase in mn-BAW variance in larger litters. These results are in contrast with ours because we associated larger litters with the most homogeneous BAW, according to quartiles distribution. In fact, Blasco et al. (2017) found a larger LS variation after 6 th parturition, confirming our results.

\section{Conclusions}

In conclusion, considering the influences of does' parity order on LS and the differences in kits' bodyweight previously described between primiparous and pluriparous, the commercial genetic centres should equalise the litters according to the birth weight, by rearing kits with light birth weight in smaller litters and those with heavier birth weight in larger litters. We also suggest the use of quartiles to divide the kits population in order to help the equalisation practice process. Further investigation is required to compare the effect of the does within each parity order and to check the possible effects of the season and the environment on the performance of commercial genetic centres.

\section{Acknowledgements}

The authors thank Dr. Daniela Frassinelli for providing professional writing services and Prof. Giulio Visentin for helping in the revising process.

\section{Disclosure statement}

No potential conflict of interest was reported by the author(s).

\section{References}

Agea I, García ML, Blasco A, Argente MJ. 2019. Litter survival differences between divergently selected lines for environmental sensitivity in rabbits. Animals. 9(9):603.

Apori SO, Hagan JK, Osei D. 2014. The growth and reproductive performance of different breeds of rabbits kept under warm and humid environments in Ghana. Online J Anim Feed Res. 4(3):51-59.

AOAC International. 2016. Official methods of analysis of AOAC International. Rockville (MD): AOAC International.

Blasco A, Martínez-Álvaro M, García ML, Ibáñez-Escriche N, Argente MJ. 2017. Selection for environmental variance of litter size in rabbits. Genet Sel Evol. 49(1):48.

Bolet G, Garreau H, Joly T, Theau-Clement M, Falières J, Hurtaud J, Bodin L. 2007. Genetic homogenisation of birth weight in rabbits: indirect selection response for uterine horn characteristics. Livest Sci. 111(1-2):28-32.

Castellini C, Dal Bosco A, Arias-Álvarez M, Lorenzo PL, Cardinali R, Rebollar PG. 2010. The main factors affecting the reproductive performance of rabbit does: a review. Anim Reprod Sci. 122(3-4):174-182.

Dalle Zotte A, Paci G. 2013. Influence of rabbit sire genetic origin, season of birth and parity order on doe and litter performance in an organic production system. Asian Australas J Anim Sci. 26(1):43-49.

De Blas JC, Mateos GG. 1998. Feed formulation. In. De Blas JC, Wiseman J, editors. The nutrition of the rabbit. 2nd ed. Wallingford (UK): CABI Publishing. p. 241-253.

Di Meo C, Gazaneo MP, Racca C, Bovera F, Piccolo G, Nizza A. 2004. Effect of birth weight and litter size on productive performance of rabbits. Asian Australas J Anim Sci. 17(8):1158-1161.

Ferguson FA, Lukefahr SD, McNitt Jl. 1997. Preweaning variables' influence on market traits in rabbit. J Anim Sci. 75(3): 611-621.

Garreau H, Bolet G, Larzul C, Robert-Granie C, Saleil G, SanCristobal M, Bodin L. 2008. Results of four generations of a canalising selection for rabbit birth weight. Livest Sci. 119(1-3):55-62.

Hamilton HH, Lukefahr SD, McNitt Jl. 1997. Maternal nest quality and its influence on litter survival and weaning 
performance in commercial rabbits. J Anim Sci. 75(4): 926-933.

Lebas F. 1975. Le lapin de chair: ses besoins nutritionalles et son alimentation pratique [The meat rabbit: its nutritional needs and its practical diet]. Paris (France): ITAVI.

Lenoir G, Garreau H, Banville M. 2012. Estimation of genetic parameters and trends for birth weight criteria in HyCole d line. Paper presented at the 10th World Rabbit Congress; Sept 3-6; Sharm El-Sheikh, Egypt

Ludwiczak A, Składanowska-Baryza J, Kuczyńska B, Stanisz M. 2020. Hycole doe milk properties and kit growth. Animals. 10(2):214.

Minuti A, Gallo A, Lopreiato V, Bruschi S, Piccioli-Cappelli F, Uboldi O, Trevisi E. 2020. Effect of litter size on prepartum metabolic and amino acidic profile in rabbit does. Animal. 14(10):2109-2115.

Parigi-Bini R, Xiccato G. 1993. Recherches sur l'interaction entre alimentation, reproduction et lactation chez la lapine, une revue. World Rabbit Sci. 1(4): 155-161.

Poigner J, Szendró Z, Lévai A, Radnai I, Biró-Nemeth E. 2000a. Effect of birth weight and litter size on growth and mortality in rabbits. World Rabbit Sci. 8(1):17-22.

Poigner J, Szendrő Z, Lévai A, Radnai I, Biró-Nemeth E. 2000b. Effect of birth weight and litter size at suckling age on reproductive performance in does as adults. World Rabbit Sci. 8(3):103-109.

Rebollar PG, Pérez-Cabal MA, Pereda N, Lorenzo PL, AriasÁlvarez M, García-Rebollar P. 2009. Effects of parity order and reproductive management on the efficiency of rabbit productive systems. Livest Sci. 121(2-3):227-233.

Sivakumar K, Thiruvenkadan AK, Kumar VRS, Muralidharan J, Singh DAP, Saravanan R, Jeyakumar M. 2013. Analysis of production and reproduction performances of Soviet Chinchilla and White Giant rabbits in tropical climatic conditions of India. World Rabbit Sci. 21(2):101-106.

Szendrö Z. 2000. The nutrition status of fetuses and suckling rabbits and its effect on their subsequent productivity: a review. Paper presented at the 7th World Rabbit Congress; July 4-5; Valencia, Spain.
Szendrő Z, Barna J. 1984. Some factors affecting mortality of suckling and growing rabbits. Paper presented at the 3rd World Rabbit Congress; April 4-8; Rome, Italy.

Szendrő Z, Biró-Nemeth E, Radnai I, Milisits G, Zimanyi A. 1996. Connection between reproductive performance and productive lifetime of rabbit does. Paper presente at the 6th World Rabbit Congress; July 9-12; Toulouse, France.

Szendrő Z, Cullere M, Atkári TD, Zotte A. 2019. The birth weight of rabbits: influencing factors and effect on behavioural, productive and reproductive traits: A review. Livest Sci. 230:103841.

Szendrő Z, Kampits E. 1985. [Connection between number of teats and production parameters of does]. Allattenyesztesi es Takarmanyozasi. 34:361-370. Hungarian.

Tůma J, Tůmová E, Valášek V. 2010. The effect of season and parity order on fertility of rabbit does and kit growth Czech J Anim Sci. 55(8):330-336.

Vasquez R, Petersen J, Mennicken L. 1997. Der einfluss des alters der häsin sowie deren milchleistung und des geburtsentwickelung während der mastperiode. Paper presented at the 10th Symposium on Housing and Diseases of Rabbits, Furbearing Animals and Pet Animals; May 14-15; Celle, Germany.

Vicente JS, García-Ximénez F, Viudes-de-Castro MP. 1995. Neonatal performances in 3 lines of rabbit (litter sizes, litter and individual weights). Ann Zootech. 44(3):255-261.

Xiccato G, Trocino A, Sartori A, Queaque PI. 2004. Effect of parity order and litter weaning age on the performance and body energy balance of rabbit does. Livest Prod Sci. 85(2-3):239-251.

Zerrouki N, Bolet G, Berchiche M, Lebas F. 2010. Evaluation of breeding performance of a local Algerian rabbit population raised in the Tizi-Ouzou area (Kabylia). World Rabbit Sci. 13(1):29-37.

Zerrouki N, Kadi SA, Lebas F, Bolet G. 2007. Characterisation of a Kabylian population of rabbits in Algeria: birth to weaning growth performance. World Rabbit Sci. 15(2): 111-114. 